\title{
PRELOAD AND TORQUE REMOVAL EVALUATION OF THREE DIFFERENT ABUTMENT SCREWS FOR SINGLE STANDING IMPLANT RESTORATIONS
}

\author{
Rafael Augusto STÜKER ${ }^{1}$, Eduardo Rolim TEIXEIRA ${ }^{2}$, João Carlos Pinheiro BECK ${ }^{3}$, Nilza Pereira da COSTA ${ }^{4}$
}

\author{
1- DDS, Graduate student, Pontifical Catholic University of Rio Grande do Sul, Porto Alegre, RS, Brazil. \\ 2- DDS, Ph.D. Associate Professor, Department of Prosthodontics, Pontifical Catholic University of Rio Grande do Sul, Porto Alegre, RS, \\ Brazil. \\ 3- Ph.D. Associate Professor, Department of Mechanical Engineering, Pontifical Catholic University of Rio Grande do Sul, Porto Alegre, RS, \\ Brazil. \\ 4- DDS, Ph.D. Associate Professor, Department of Clinical Dentistry, Pontifical Catholic University of Rio Grande do Sul, Porto Alegre, RS,
} Brazil.

Corresponding address: Rafael Augusto Stüker - Rod. Dr. Antônio Luiz M. Gonzaga, 4081 - sala 14. Bairro Rio Tavares, Florianópolis-SC 88048-300 - e-mail: rafaelstuker@yahoo.com.br - Phone: 55 48- 33344459

Received: May 18, 2007 - Modification: September 18, 2007 - Accepted: October 19, 2007

\begin{abstract}
$S$

everal authors still consider the mechanical problems of fracture and component loosening as the main causes of failure of implant-supported restorations. The purpose of this in vitro study was to compare the preload of three types of screw for transmucosal abutment attachment used in single implant-supported prosthesis through strain gauge and removal torque measurements. Three external hex fixtures were used, and each received a transmucosal abutment (Cera One ${ }^{\circledR}$ ), which was fixed to the implant with its respective screw: Group A- gold screw, Group B- titanium screw and Group C- surface-treated titanium screw $\left(\right.$ Ti-Tite $\left.{ }^{\circledast}\right)$. Ten screws of each type were attached applying a $30.07 \pm 0.28 \mathrm{Ncm}$ torque force and maintained in position for 5 minutes. After this, the preload values were measured using strain gauges and a measurement cell. Gold screws presented higher preload values $(131.72 \pm 8.98 \mathrm{~N})$, followed by surface-treated titanium screws $(97.78 \pm 4.68 \mathrm{~N})$ and titanium screws $(37.03 \pm 5.69$ $\mathrm{N})$. ANOVA $(\mathrm{p}<0.05)$ and Tukey's test $(\mathrm{p}<0.05)$ were applied. Statistically significant differences were found among the groups for both preload and removal torque values. In conclusion, gold screws may be indicated to achieve superior longevity of the abutment-implant connection and, consequently, prosthetic restoration due to greater preload values yielded.
\end{abstract}

Uniterms: Dental implants. Dental prosthesis. Torque. Screw. Abutment.

\section{INTRODUCTION}

The development of titanium fixtures has brought several benefits for the rehabilitation of edentulous patients. When biological and mechanical principles are respected, this treatment modality may successfully restore the functional and esthetic impairments caused by tooth loss ${ }^{3}$.

In spite of the significant evolution of a number of implant systems, implant design and features, such as those related to the mechanical behavior of implant-supported prostheses, should be improved. Dental prostheses do fail during function mainly due to abutment and prosthesis screw loosening and/ or fracture. In addition, it has been reported that abutment screw loosening is only surpassed by loss of osseointegration as the main cause of failure on implant-supported restorations, as shown in longitudinal follow-up studies ${ }^{5}$.

When two metal surfaces are in contact, adhesion and friction forces do limit the movement between them. An applied method aimed to reduce this friction and improve adhesion consists of interposing a lubricating film between these surfaces. A metal with low shear strength, such as pure gold, may act as a dry lubricant. When compared to screws without gold coating, it has been found that gold-coated abutment screws subjected to torques of 12,20 , and $32 \mathrm{Ncm}$ aiming a $0.0064 \mathrm{~mm}$ opening of the implant-abutment interface presented 26, 24, and 24\% of preload increase, respectively ${ }^{7}$.

In another study, it was found that when a torque force is applied to an abutment screw, a significant part of this force is lost due to friction between the contact points of metal surfaces, inhibiting the rotation of the screw. Thus, decreasing of friction between metallic surfaces may increase the screw rotation and, consequently, the preload. The rotation of goldcoated abutment screws placed with torque forces of 12, 20, and $32 \mathrm{Ncm}$ increased 73, 76, and 62\%, respectively, when compared to titanium abutment screws ${ }^{2}$.

The purpose of this study was to evaluate by strain 
gauges the preload and torque removal values on three abutment screws (gold, titanium, and titanium with surface treatment screws) applying an equivalent torque force $(30.07 \pm 0.28 \mathrm{Ncm})$.

\section{MATERIALAND METHODS}

Three machined self-tapping external hex titanium screws with $4 \mathrm{~mm}$ in diameter and $15 \mathrm{~mm}$ in length were used in this investigation (Master Screw ${ }^{\circledR}$, Conexão ${ }^{\circledR}$ Sistemas de Prótese Ltda., São Paulo, Brazil, reference 517415, batch \#5010345031).

Three transmucosal Cera One ${ }^{\circledR}$ type abutments $(2.0 \mathrm{~mm}$ height, Cera One ${ }^{\circledR}$, Conexão ${ }^{\circledR}$ Sistemas de Prótese Ltda., reference 045022, batch \#5080915121), designed for cemented single standing implant-supported restorations were also used.

The transmucosal abutments were attached to the fixtures using 10 gold screws (Conexão ${ }^{\circledR}$, Sistemas de Prótese Ltda., reference 121022, batch \#5073147) (Figure 1a A), 10 titanium screws (Conexão ${ }^{\circledR}$ Sistemas de Prótese Ltda., reference 121024, batch \#5063223) (Figure 1a B), and 10 surface treated titanium screws (Ti-tite ${ }^{\circledR}$, Conexão ${ }^{\circledR}$ Sistemas de Prótese Ltda., reference 121026, batch \#5063035) (Figure 1a C).

A load cell adapted from a model described in the literature was developed for preload and torque removal assessments ${ }^{9}$. This load cell presented a central void for fixture fixation in its upper portion and a horizontal plate for fixation of four strain gauges on its lower portion (Figure $1 \mathrm{~b}$ ).

The abutments were placed on the upper plate of the cell (Figure $1 \mathrm{c}$ ) in such way that the contact between abutments and fixtures was free of any interference. The fixture, the central void and the plate constitute a single unit. Therefore, when the abutment was fixed to the fixture by the abutment screw, tensions generated by this fixation pulled the unit against the abutment, producing a deformation in the lower plate connected to the strain gauges. Next, the force (preload) generated on the abutment screws was captured by the strain gauges in volts $(\mathrm{V})$ and later converted to Newton $(\mathrm{N})$.

The aforementioned sample was arranged into 3 different groups according to the characteristics of each abutment screw: Group A was formed by gold screws, Group B was formed by titanium screws, and Group $\mathrm{C}$ was formed by surface-treated titanium screws.

To determine fixation and removal torques, a digital torquemeter was used (Torqueleader ${ }^{\circledR}$, model TSD150, Type I, class E, part\#117317), previously calibrated according with ISO 6789:2003 (E) standard. A square hand wrench (1.27 mm diameter, Conexão ${ }^{\circledR}$, Sistemas de Prótese Ltda., reference 062300, batch \#5091632) was attached to the torquemeter to allow proper connection between torquemeter and screws (Figure 1d).

Following the proper assembly of fixture and abutment on Group A, the gold screw was then attached to the fixture with an applied torque force of $30.07 \pm 0.28 \mathrm{Ncm}$, being repeated afterwards for groups B and C. Then, the initial preload value for the abutment screws was determined (in volts) and all screws were kept in their positions for 5 minutes for preload stabilization, according to the literature ${ }^{9}$. During this the preload stabilization period, preload values were obtained after 1, 2, 3, 4, and 5 minutes after fixation, and thereafter a mean value was calculated. After this evaluation, the abutment screw was removed using a digital torquemeter and the maximum value of reverse torque force required for screw removal was recorded in $\mathrm{Ncm}$. Next, the same screw was fixed again another 4 times, obtaining the preload and torque removal mean values. Nine other screws from group $A$ as well as 10 other screws from $B$ and $C$ groups were subjected to the same procedure described above.

The values of fixation torque forces of the 3 groups were analyzed statistically by to one-way analysis of variance (ANOVA). Comparison of preload values within groups was possible using the mean of 6 measurements ( 0 to 5 minutes) obtained at the first abutment fixation, using two-way ANOVA. One-way ANOVA was used to compare the mean preload values among the groups. Tukey's test was used for multiple comparisons among the groups. For all statistical tests, significance level was set at $5 \%$.

All fixations for each screw $(n=5)$ were considered for evaluation of the torque removal to obtain an average value, and the statistical analysis was performed similarly to the preload data. Two-way ANOVA was used to evaluate the mean torque removal among the groups, and one-way ANOVA to evaluate the differences between screws. Tukey's multiple comparison test was used for individual comparisons among the groups. For all statistical tests, significance level was set at $5 \%$.

\section{RESULTS}

The mean fixation torque force when all screws were considered was $30.07 \pm 0.28 \mathrm{Ncm}$ (C.I. $95 \%$ (30.03; 30.17)). There were no statistically significant differences $(\mathrm{p}=0.1244)$ among the groups regarding the fixation torque.

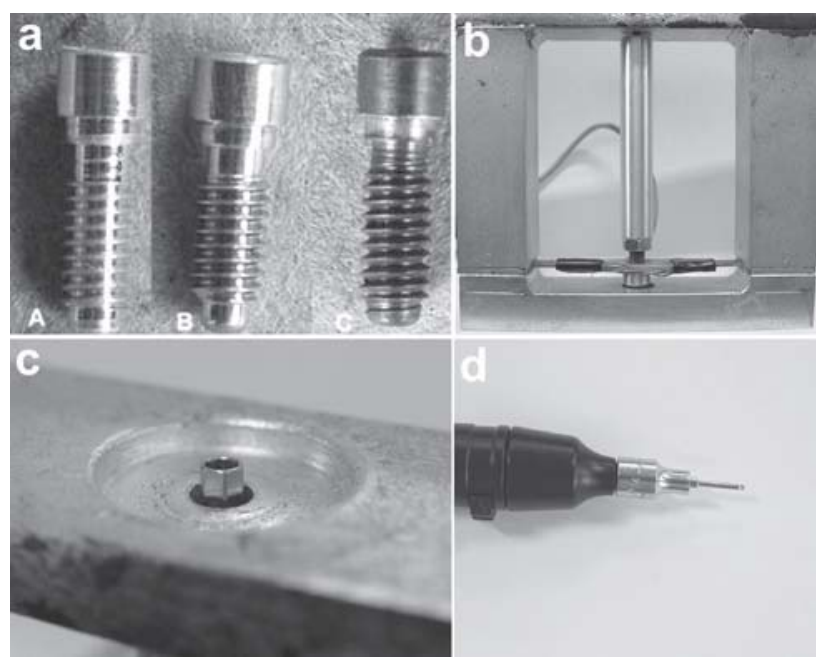

FIGURE 1- a) Gold (A), titanium (B) and Surface-treated titanium (C) abutment screws (Conexão ${ }^{\circledR}$, Sistemas de Prótese Ltda., São Paulo, Brazil); b) Load cell adapted from the literature; c) Cera One ${ }^{\circledR}$ abutment in position; d) Square hand wrench attached to the torquemeter 


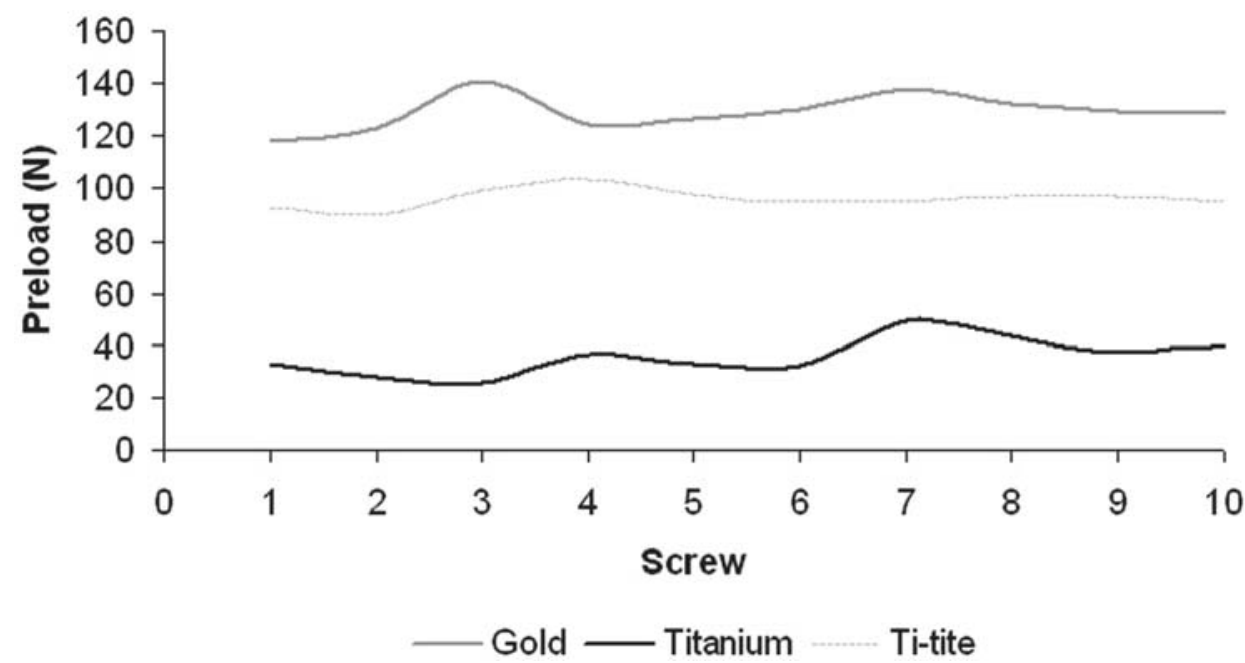

FIGURE 2- Preload averages of each analyzed group

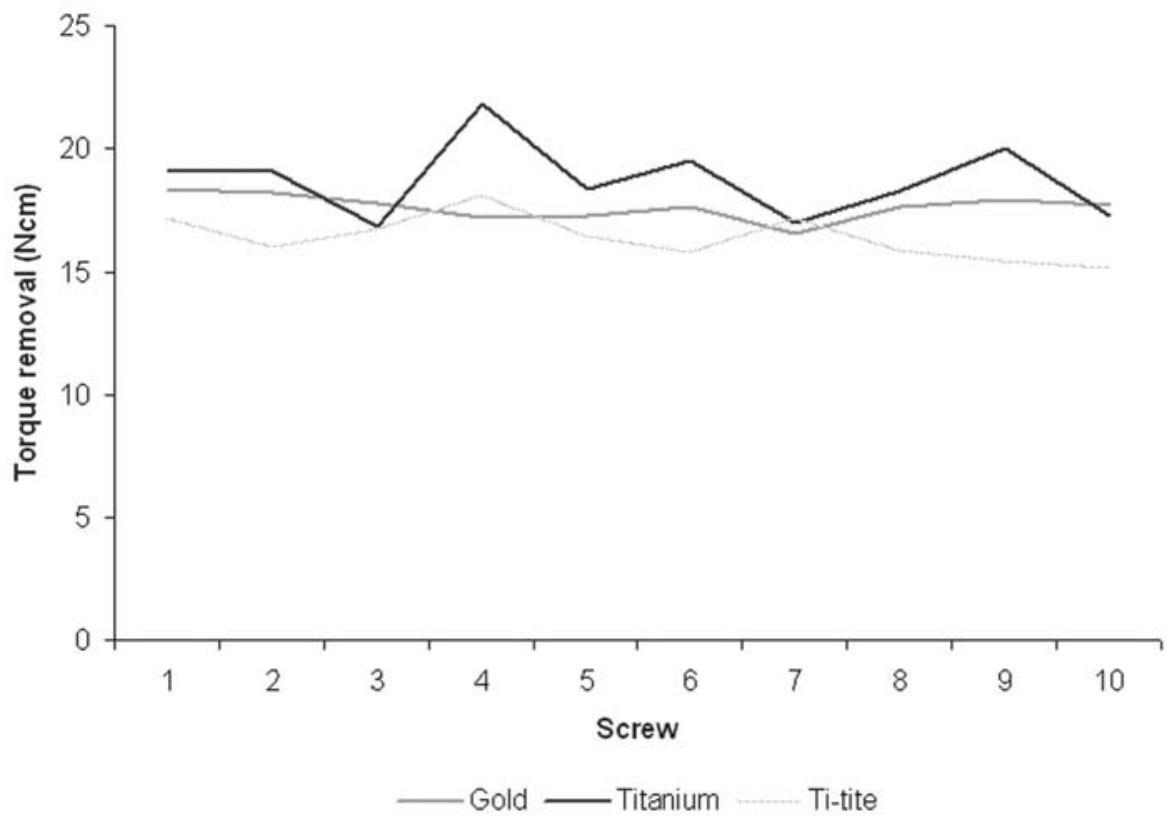

FIGURE 3- Torque removal averages of three analyzed groups

Preload values for the 3 groups showed significant differences $(\mathrm{p}<0.01)$. The gold screws presented the highest preload values and the titanium screws the lowest values (Figure 2).

The mean preload values of the gold screws was $131.72 \pm 8.98 \mathrm{~N}$, and presented statistically significant differences $(\mathrm{p}<0.01)$ compared to groups B and C. Screw \#3 and screw \#1 presented the highest $(140.48 \mathrm{~N})$ and the lowest $(117.73 \mathrm{~N})$ preload values, respectively. The titanium screws presented statistically significant differences $(\mathrm{p}<0.01)$ (mean $37.03 \pm 5.69 \mathrm{~N}$ ). The highest preload value was obtained for screw \#7 (49.68 N), while screw \#3 presented the lowest value $(25.30 \mathrm{~N})$. In the group of surface-treated titanium screws, the mean preload value was $97.78 \pm 4.68 \mathrm{~N}$. Statistically significant differences $(p<0.01)$ were also observed in this group, (maximum: $104.09 \mathrm{~N}$ for screw \#4; minimum: $90.28 \mathrm{~N}$ for screw \#2).
The removal torque presented statistically significant differences among the analyzed materials $(\mathrm{p}<0.001)$ (Figure 3 ). The gold screws presented a mean removal torque of $17.64 \pm 1.12 \mathrm{Ncm}$, i.e. they did not shown statistically significant differences $(\mathrm{p}=0.3713)$. Titanium screws presented a mean removal torque of $18.75 \pm 1.89 \mathrm{Ncm}$, and showed statistically significant differences $(\mathrm{p}<0.001)$. The group of surface-treated titanium screws present statistically significant difference $(\mathrm{p}=0.004)$ (mean: $16.43 \pm 1.33 \mathrm{Ncm})$.

\section{DISCUSSION}

The results of this study are similar to those of previous investigations $s^{4,8}$, which found statistically higher preload values for gold fixation screws in comparison to other tested materials, in spite of using different methodologies and 
materials. Amaximum preload value of $666.4 \mathrm{~N}$ for gold screws and $458.2 \mathrm{~N}$ for titanium screws was reported ${ }^{8}$. In addition, the finds of the present study suggest that the evaluated surface treatment of titanium screws was effective, since these screws presented higher preload values than conventional titanium screws.

Most previously published reports in the dental literature do not specify the removal torque of abutment screws. The effect of different cyclic loads has been evaluated using a 32 $\mathrm{Ncm}$ torque for fixation of the screws, which was repeated after 10 minutes to avoid contact relaxation ${ }^{6}$. Several manufacturers have suggested this clinical approach to decrease screw loosening.

In the present study, to allow a direct comparison between results of preload and torque removal for the studied groups, all screws received a similar fixation torque of $30.07 \pm 0.28 \mathrm{Ncm}$, despite the manufacturer's recommendations of using $35 \mathrm{Ncm}$ torque for the Ti-tite ${ }^{\circledR}$ screws. This was performed to eliminate a possible bias caused by elastic deformation that might occur in titanium screws during fixation, which might not only quantitatively but qualitatively influence the study outcomes and impair comparison among groups. This approach allowed that, in this investigation, only the screw was left as a study variable.

Another relevant issue is that up to $10 \%$ of the initial preload may be lost to smooth contact surfaces (embedment relaxation), rather than elongation stresses. However, it has been previously observed that when the same screw is fixed several times, its preload values increased ${ }^{4}$.

Comparison to different results obtained in other studies might be a difficult task due to variations of tested products and variables that may influence the produced preload value, such as the elastic modulus of the screws, opposing joint surfaces, abutment design, friction coefficient, lubrication, rate of the applied torque and the adaptation between the fixture hexagon and the abutment ${ }^{2}$. The findings of the present study suggest a trend for greater preload values verified for gold screws, followed by surface-treated titanium screws and titanium screws, confirming the outcomes of previous investigations $\mathrm{s}^{4,8}$.

Finite element analysis has been used to evaluate preloading through elongation of the abutment screw. A study evaluating the preload of two different systems of the same implant manufacturer in function, found that the optimal preload produced should be $75 \%$ of the screw yield stress, and also that the preload value increases dramatically as the friction coefficient between implant and screw decreases ${ }^{7}$.

As loosening of implant/abutment joint causes clinical problems, another question that may be raised is whether the torque values recommended by the manufacturers should be increased in order to obtain greater longevity of screw tightening.

The preload produced by gold or titanium fixation screws can be evaluated through the measurement of elongation stresses. It has been found that the stresses were $60 \%$ lower than the strengths against the torques applied according to the manufacturer's instructions ${ }^{4}$. On the other hand, it has been reported that gold or titanium screws could support higher torques than those indicated by the manufacturers without presenting plastic deformations, although it has been recommended elsewhere that the stresses should not exceed $65 \%$ of the screw's fracture strength ${ }^{1}$.

Although the results of this study showed that gold screws have a clear superiority of the produced preload, application of cyclic loads would be required for a closer simulation of the masticatory function on implanted-supported restorations.

\section{CONCLUSIONS}

It may be concluded: 1 . Gold should be the material of choice for abutment fixation screws, since it produced the highest preload values, followed by surface-treated titanium screws and conventional titanium screws; 2 . Titanium screws presented the highest torque removal values, followed by gold screws, and surface-treated titanium screws.

\section{REFERENCES}

1- Al Rafee MA, Nagy WW, Fournelle RA, Dhuru VB, Tzenakis GK, Pechous CE. The effect of repeated torque on the ultimate tensile strength of slotted gold prosthetic screws. J Prosthet Dent. 2002;88(2):176-82.

2- Cantwell A, Hobkirk JA. Preload loss in gold prosthesis-retaining screws as a function of time. Int J Oral Maxillofac Implants. 2004; 19(1):124-32.

3- Carr AB, Brunski JB, Hurley E. Effects of fabrication, finishing, and polishing procedures on preload in prostheses using conventional gold and plastic cylinders. Int J Oral Maxillofac Implants. 1996;11(5):58998

4- Haack JE, Sakaguchi RL, Sun T, Coffey JP. Elongation and preload stress in dental implant abutment screws. Int J Oral Maxillofac Implants. $1995 ; 10(5): 529-36$.

5- Hoyer SA, Stanford CM, Buranadham S, Fridrich T, Wagner J , Gratton D. Dynamic fatigue properties of the dental implant-abutment interface: Joint opening in wide-diameter versus standard-diameter hex-type implants. J Prosthet Dent. 2001;85(6):599-607.

6- Khraisat A, Hashimoto A, Nomura S, Miyakawa O. Effect of lateral cyclic loading on abutment screw loosening of an external hexagon implant system. J Prosthet Dent. 2004;91(4):326-34

7- Lang LA, Kang B, Wang RF, Lang BR. Finite element analysis to determine implant preload. J Prosthet Dent. 2003;90(6):539-46.

8- Tan KB, Nicholls JI. Implant-Abutment screw joint preload of 7 Hex-top abutment systems. Int J Oral Maxillofac Implants. 2001;16(3):367-77.

9- Tzenakis GK, Nagy WW, Fournelle RA, Dhuru VB. The effect of repeated torque and salivary contamination on the preload of slotted gold implant prosthetic screws. J Prosthet Dent. 2002;88(2):183-91. 